\title{
Study on Eutrophic Levels and Microcystins Characteristics in Dianchi Lake and Erhai Lake, China
}

\author{
Qiong LIANG \\ Beijing Key Laboratory of New Technique in Agricultural \\ Application \\ Plant Science and Technology College, Beijing University \\ of Agriculture \\ Beijing, 102206, China \\ e-mail: liangqiong84@163.com
}

\author{
Yuan ZHANG \\ Hebei Provincial Academy of Environmental Science \\ Shijiazhuang, Hebei, 050037, China
}

\section{Yun LIU}

Beijing Key Laboratory of New Technique in Agricultural Application Plant Science and Technology College, Beijing University of Agriculture Beijing, 102206, China e-mail: housqly@126.com

\begin{abstract}
The water quality parameters and microcystins of the two largest highland lakes in China, Dianchi Lake and Erhai Lake, were determined during high eutrophication season in 2011. The results showed that the eutrophic levels and MCs concentrations were obviously higher in Dianchi Lake than those in Erhai Lake. The MC-YR and -LR were significantly correlated with TN, TP, Chl-a and TOC in Dianchi Lake. Thus, a proper eutrophication control should be considered to ensure safe and long-term use of the lake water.
\end{abstract}

Keywords-eutrophication; mcrocystins; highland lake

\section{INTRODUCTION}

The eutrophication of water bodies has become a worldwide environmental problem in recent years. With the rapid economic growth, urban expansion, and agriculture development in China, the eutrophication problems become more and more severe, especially in the lakes and reservoirs [1]. Microcystins (MCs) are hepatotoxins produced by cyanobacterial water bloom, which are toxic to aquatic fauna and have been recognized as a public health threat[2,3]. Previous studies have shown that MCs concentrations could be influenced by many factors such as sunlight, temperature, $\mathrm{pH}, \mathrm{N}, \mathrm{P}$, microelements and aquatic organism [4-6], and change with the season [7].

Dianchi Lake and Erhai Lake are the two largest highland lakes located in Yunnan province on the Yunnan-Guizhou Plateau, China (Figure 1). Both of them are suffering from eutrophication since the 1990s. The Dianchi Lake covers 298 $\mathrm{km}^{2}$ of water area, with an average depth of $4.4 \mathrm{~m}$. In the past decades, much of the wetlands around the lake have been destroyed by filling in with soil for agricultural production. The water in Dianchi Lake is now undrinkable because of water quality deterioration caused by agricultural runoff pollutants. The Erhai Lake covers $250 \mathrm{~km}^{2}$ of water area, and the water quality of which is good as a whole. However, the water ecosystem of Erhai Lake showed an obvious degenerating trend in recent years [8]. In 1996 and 2003, Erhai Lake experienced two large-scale blue algae blooms, and triggered problems in drinking water supply. Considering the possible toxicity of MCs to water ecosystem and human health, the research on the characteristics of MCs in the two lakes is therefore necessary.

The present study was based on the analysis of water quality of Dianchi Lake and Erhai Lake during high eutrophication season. The objectives of this study were: (1) to compare the eutrophic levels and MCs pollution in the two lakes; (2) to investigate the correlation of MCs with water quality indicators.

\section{MATERIALS AND METHODS}

Water samples were collected using brown glass collector from late September to early October, during high eutrophication season in 2011 (Figure 1). The water quality parameters, including $\mathrm{SD}, \mathrm{pH}, \mathrm{DO}, \mathrm{TN}, \mathrm{NH}_{3}-\mathrm{N}, \mathrm{TP}, \mathrm{PO}_{4}{ }^{3-}$ and $\mathrm{Chl}-a$, were determined according to the national standard methods. TOC was determined by a TOC-VSH analyzer (SHIMADZU). Five kinds of MCs (MC-RR, -YR, LR, -LA and -LY) were determined using an Agilent 1260 High Performance Liquid Chromatography (HPLC). 
The trophic level index (TLI) was used to assess the eutrophication levels of Dianchi lake and Erhai Lake. Four water quality parameters (TP, TN, SD and Chl- $a$ ) were selected to evaluate TLI value, as in Eq. (1) and (2).

$$
\begin{gathered}
T L I=\sum_{j=1}^{m} W_{j} \cdot T L I_{j} \\
W_{j}=r_{i j}^{2} / \sum_{j=1}^{m} r_{i j}^{2}
\end{gathered}
$$

$\mathrm{TLI}_{\mathrm{j}}$ is the trophic level index for the parameter $\mathrm{j} ; \mathrm{W}_{\mathrm{j}}$ is the relative weight of trophic level index for the parameter $\mathrm{j}$; $\mathrm{r}_{\mathrm{ij}}$ is the correlation between Chl- $a$ and the parameter $\mathrm{j}$. The calculation of $\mathrm{TLI}_{\mathrm{j}}$ and values of $\mathrm{r}_{\mathrm{ij}}$ and $\mathrm{r}_{\mathrm{ij}}{ }^{2}$ are according to Jin et al. [9]

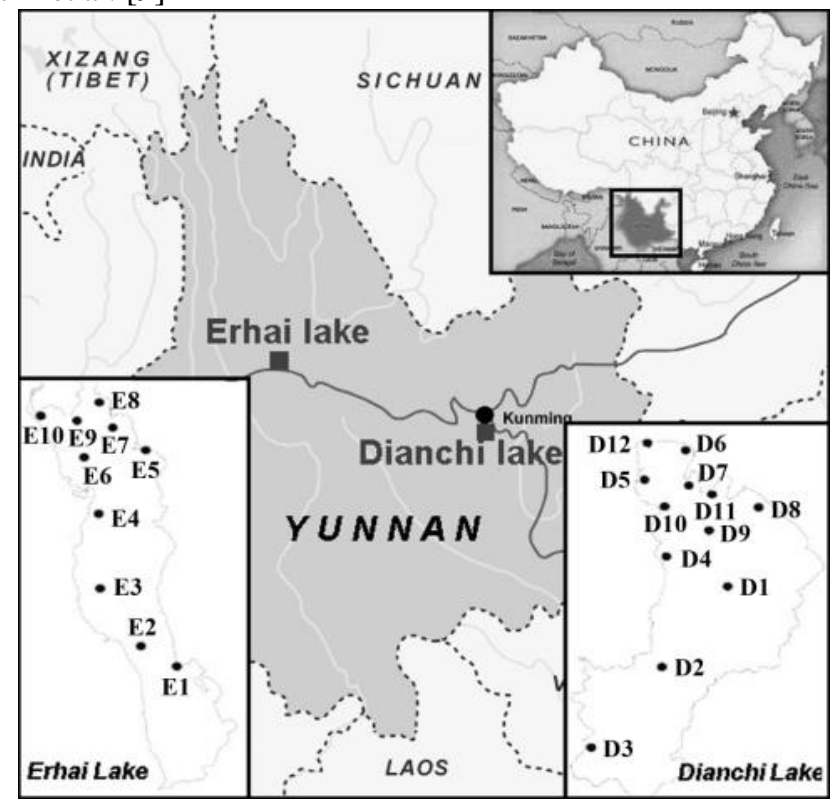

Figure 1. Locations of Dianchi Lake and Erhai Lake and the sampling sites in the two lakes.

The levels of eutrophication were defined as oligotropher (TLI $<30)$, mesotropher $(30 \leq \mathrm{TLI} \leq 50)$, light eutropher $(50$ $<\mathrm{TLI} \leq 60)$, middle eutropher $(60<\mathrm{TLI} \leq 70)$ and hyper eutropher (TLI > 70).

Spearman's rank-order correlation and principal component analysis (PCA) were performed with SPSS Statistics version 17 (Chicago, IL).

\section{RESULTS AND DISCUSSION}

\section{A. Characteristics of Water Quality in Dianchi Lake and Erhai Lake}

Descriptive statistics for all water quality parameters examined were shown in Table I. The average concentrations of $\mathrm{TN}, \mathrm{NH}_{3}-\mathrm{N}, \mathrm{PO}_{4}{ }^{3-}$ and Chl- $a$ were lower in Erhai than those in Dianchi Lake, indicating a better water quality of Erhai Lake. This was also supported by the higher SD value in Erhai (187.0) as compared to that in Dianchi Lake (29.2).
However, the concentrations of TP and TOC were higher in Erhai than those in Dianchi Lake. The TP concentrations in both lakes exceeded the limit values in Environmental Quality Standard for Surface Water (GB3838-2002, class V criteria, $0.2 \mathrm{mg} \mathrm{L}^{-1}$ ), suggesting a potential risk of eutrophication in these lakes. The $\mathrm{TN}$ concentrations in Dianchi Lake also exceeded the limit values (GB3838-2002, class $\mathrm{V}$ criteria, $2.0 \mathrm{mg} \mathrm{L}^{-1}$ ).

The PCA results showed two principal components (PCs) for the water quality parameters of Dianchi Lake, accounting for $58.24 \%$ and $21.46 \%$ of the total variation, respectively (Table II). TN, TP, Chl- $a$ and TOC were the highly weighted variables under $\mathrm{PC} 1$, suggesting that this component was correlated with agricultural pollutants and aquatic organisms. The highly weighted variables under $\mathrm{PC} 2$ were $\mathrm{NH}_{3}-\mathrm{N}$ and $\mathrm{PO}_{4}{ }^{3-}$, which were determined by dissolved nutrients. For the Erhai Lake, three PCs were extracted which accounting for $43.83 \%, 16.12 \%$ and $14.26 \%$ of the data variation, respectively. The highly weighted variables were shown in Table II.

TABLE I. DESCRIPTIVE STATISTICS OF WATER QUALITY

\begin{tabular}{|c|c|c|c|c|c|c|}
\hline \multirow{2}{*}{ Parameters } & \multicolumn{3}{|c|}{ Dianchi Lake $(n=12)$} & \multicolumn{3}{|c|}{ Erhai Lake $(\mathrm{n}=10)$} \\
\hline & Range & Mean & S.D. & Range & Mean & S.D. \\
\hline $\mathrm{SD}, \mathrm{cm}$ & $10.0-50.0$ & 29.2 & 10.6 & $160.0-210.0$ & 187.0 & 17.7 \\
\hline $\mathrm{pH}$ & $9.04-9.53$ & 9.36 & 0.14 & $8.05-8.75$ & 8.53 & 0.22 \\
\hline $\mathrm{DO}, \mathrm{mg} \mathrm{L}^{-1}$ & $5.88-10.84$ & 7.97 & 1.39 & $5.58-6.53$ & 5.99 & 0.32 \\
\hline $\mathrm{TN}, \mathrm{mg} \mathrm{L}^{-1}$ & $2.29-12.26$ & 4.51 & 2.63 & $0.74-1.18$ & 0.95 & 0.17 \\
\hline $\mathrm{NH}_{3}-\mathrm{N}, \mathrm{mg} \mathrm{L}^{-1}$ & $0.09-0.58$ & 0.37 & 0.14 & $0.17-0.26$ & 0.20 & 0.03 \\
\hline $\mathrm{TP}, \mathrm{mg} \mathrm{L}^{-1}$ & $0.14-0.72$ & 0.28 & 0.15 & $0.38-4.24$ & 1.98 & 1.56 \\
\hline $\mathrm{PO}_{4}{ }^{3-}, \mathrm{mg} \mathrm{L}^{-1}$ & $0.00-0.05$ & 0.02 & 0.01 & $0.00-0.04$ & 0.01 & 0.01 \\
\hline $\mathrm{Chl}-a, \mathrm{mg} \mathrm{m}^{-3}$ & $50.78-517.59$ & 128.22 & 126.54 & $6.83-10.97$ & 8.62 & 1.38 \\
\hline $\mathrm{TOC}, \mathrm{mg} \mathrm{L}^{-1}$ & $6.04-44.61$ & 12.55 & 10.84 & $19.22-31.62$ & 25.11 & 4.21 \\
\hline
\end{tabular}
PARAMETERS OF DIANCHI LAKE AND ERHAI LAKE.

TABLE II. RESUlTS OF PCA FOR MICROCYSTIN CONCENTRATIONS AND ENVIRONMENTAL PARAMETERS.

\begin{tabular}{lllll}
\hline Lake & PC & $\begin{array}{l}\text { Highly weighted } \\
\text { variables }\end{array}$ & Eigenvalue & $\begin{array}{l}\text { Cumulative } \\
\text { variation (\%) }\end{array}$ \\
\hline Dianchi & PC1 & TN, TP, Chl- $a$, TOC & 5.242 & 58.24 \\
& PC2 & $\mathrm{NH}_{3}-\mathrm{N}, \mathrm{PO}_{4}{ }^{3-}$ & 1.932 & 79.70 \\
Erhai & $\mathrm{PC} 1$ & $\mathrm{NH}_{3}-\mathrm{N}, \mathrm{TOC}^{-}$ & 2.960 & 32.89 \\
& $\mathrm{PC} 2$ & $\mathrm{SD}, \mathrm{Chl}-a$ & 2.433 & 59.92 \\
& $\mathrm{PC} 3$ & $\mathrm{PO}_{4}{ }^{3-}$ & 1.918 & 81.23 \\
\hline
\end{tabular}

\section{B. Trophic Level Index}

The TLI of the water from each sampling site was calculated to evaluate the eutrophication levels of the two lakes. The average TLI values of Dianchi Lake and Erhai Lake were 75.38 and 59.08, indicating that the eutrophication levels of Dianchi Lake and Erhai Lake were hyper eutropher and light eutropher, respectively. There was a clear spatial variability of nutritional states in the Dianchi Lake. The highest value of TLI was observed in site D12 (93.57) followed by D9 (78.50) and D11 (78.41), showing a severe eutrophication in the northern part of Dianchi Lake. On the other hand, the TLI in the central and southern parts (D1-D3) of Dianchi Lake were relatively low (67.05-69.61), indicating that these areas were at middle eutropher. There were only slight variations of the TLI values (53.58-64.80) 
among different sites in Erhai Lake, showing an homogenous spatial distribution of eutrophication levels.

\section{Levels of MCs in Dianchi Lake and Erhai Lake}

The MCs levels of Dianchi Lake and Erhai Lake are shown in Figure 2. The average concentrations of MC-RR, YR, -LR, -LA and -LY in Dianchi Lake were 0.060, 0.051, $0.046,0.035,0.016 \mu \mathrm{g} \mathrm{L}^{-1}$, respectively. The highest concentrations of MC-RR $\left(0.090 \mu \mathrm{g} \mathrm{L}^{-1}\right),-\mathrm{YR}\left(0.101 \mu \mathrm{g} \mathrm{L}^{-1}\right)$, and -LR $\left(0.099 \mu \mathrm{g} \mathrm{L}^{-1}\right)$ were detected at site D12, while those of MC-LA $\left(0.068 \mu \mathrm{g} \mathrm{L}^{-1}\right)$ and -LY $\left(0.093 \mu \mathrm{g} \mathrm{L}^{-1}\right)$ were detected at D10 and D4, respectively. In the Erhai Lake, only MC-RR, -YR and -LR yielded high detection rates. Average concentrations of MC-RR, -YR and -LR were $0.028,0.031$ and $0.015 \mu \mathrm{g} \mathrm{L}^{-1}$, respectively, which were lower than those in Dianchi Lake. The highest concentrations of MC-RR and YR were detected at site E10, and that of MC-LR was detected at E6. In addition, the MCs concentrations in both lakes did not exceed the limit value of the Standards for drinking Water Quality (GB5749-2006, $\left.1 \mu \mathrm{g} \mathrm{L}^{-1}\right)$.
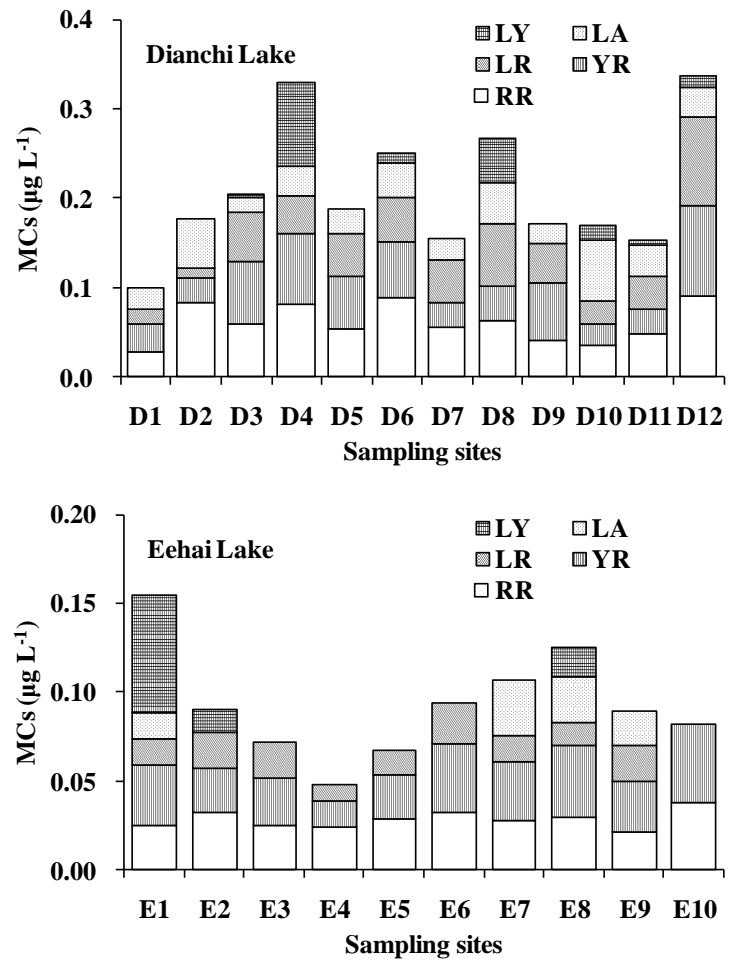

Figure 2. The MCs concentrations of Dianchi Lake and Erhai Lake.

\section{Correlations between MCs and Water Quality Parameters}

The correlation analysis showed that there was no significant correlation between water quality parameters and MC-RR or -LY in both lakes. In Dianchi Lake, MC-YR and -LR were significantly correlated with TN, TP, Chl- $a$ and TOC (MC-YR at P $<0.05$ and MC-LR at $\mathrm{P}<0.01$ ), while both MC-YR and -LR were significantly correlated with TLI $(\mathrm{P}<0.05)$. In Erhai Lake, MC-YR was significantly correlated with $\mathrm{pH}, \mathrm{NH}_{3}-\mathrm{N}$ and TOC $(\mathrm{P}<0.01)$. The significant correlations between MCs and water quality parameters suggested that a high nutritional state is favorable for the growth of harmful algae in the water bodies [10]. Since $\mathrm{N}$ is a necessary element for the growth of algae [11], the lack of $\mathrm{N}$ will depress the algae growth and MCs production [12]. In the present study, the TN concentrations in both the lakes were relatively low, and only MC-YR and LR had significant positive correlations with TN in Dianchi Lake.

Phosphorus pollution is an important cause of eutrophication in water bodies. The TP concentration was much higher in Erhai Lake (1.98 $\left.\mathrm{mg} \mathrm{L}^{-1}\right)$ than that in Dianchi Lake $\left(0.28 \mathrm{~m} \mathrm{~L}^{-1}\right)$. However, the MCs concentrations were detected higher in the latter. This was in consist with the results of Cabrol et al. [13]: the MCs levels increased with increasing $\mathrm{P}$ levels when the concentration of $\mathrm{P}$ is in the range of 0.1-0.4 $\mathrm{mg} \mathrm{L}^{-1}$, but the promoting effects became unobvious when $\mathrm{P}$ concentration is higher.

Furthermore, the MC-RR, -YR and -LR were significantly correlated with each other in Dianchi Lake, while MC-RR was significantly correlated with MC-YR in Erhai Lake $(\mathrm{P}<0.05)$, suggesting that they are closely interrelated.

\section{CONCLUSIONS}

Dianchi Lake and Erhai Lake are the two largest highland lakes located on the Yunnan-Guizhou Plateau, China. Although both of them are typical eutrophicated highland lakes, the MCs levels and its distribution characteristics are different with each other. Comparing with Erhai Lake, Dianchi Lake had higher eutrophic level and MCs concentrations. Therefore, a proper eutrophication control based on periodic monitoring of water quality parameters should be considered to ensure safe and long-term use of the lake water.

\section{ACKNOWLEDGMENTS}

The authors sincerely acknowledge the support of the Beijing Talents Cultivation and Funding Program (No. 2015000020124G055) and the Young Teachers Scientific Research Foundation of Beijing University of Agriculture (No. SXQN2016103).

\section{REFERENCES}

[1] Q. J. Xu, W. M. Chen and G. Gao, Seasonal variations in microcystin concentrations in Lake Taihu, China. Environ. Monit. Assess. 145, 75 (2008).

[2] A. Bandyopadhyay, Air pollution prevention and control: Bioreactors and bioenergy. Clean-Soil Air Water 41, 934 (2013).

[3] Y. Zhao, Q. Xue, X. Su, L. Xie, Y. Yan, L. Wang and A .D. Steinman, First identification of the toxicity of microcystins on pancreatic islet function in humans and the involved potential biomarkers. Environ. Sci. Technol. 50, 3137 (2016).

[4] Y. W. Chen, B. Q. Qin, K. Teubner and M. Dokulil, Long-term dynamics of phytoplankton assemblages: Microcystis-domination in Lake Taihu, a large shallow lake in China. J. Plankton Res. 25, 445 (2003).

[5] W. Ruangyuttikarn, I. Miksik, J. Pekkoh, Y. Peerapornpisal and Z. Deyl, Reversed-phase liquid chromatographic-mass spectrometric determination of microcystin-LR in cyanobacteria blooms under alkaline conditions. J. Chromatogr. B 800, 315 (2004). 
[6] M. Dai, P. Xie, G. D. Liang, J. Chen and H. H. Lei, Simultaneous determination of microcystin-LR and its glutathione conjugate in fish tissues by liquid chromatography-tandem mass spectrometry. $J$. Chromatogr. B 862, 43 (2008).

[7] Y. W. Chen, B. Q. Qin and X. Y. Cai, Prediction of blue-green algal bloom using stepwise multiple regressions between algae and related environmental factors in Meiliang Bay. Lake Taihu. J. Lake Sci. 13, 63 (2001). (in Chinese)

[8] S. Wang, L. Zhang and L. Ni, Ecological degeneration of the Erhai Lake and prevention measures. Environ. Earth Sci. 74, 3839 (2015).

[9] X. C. Jin, S. K. Liu and Z. S. Zhan (eds.), Lakes in China research of their environment (China Ocean Press, Beijing, 1995).
[10] D. Wu, X. Quan, Y. Zhang and Y. Zhao, Long-term operation of a compost-based biofilter for biological removal of n-butyl acetate, pxylene and ammonia gas from an air stream. Biochem. Eng. J. 32, 84 (2006).

[11] C. Kennes, E. R. Rene and M. C. Veiga, Bioprocesses for air pollution control. J. Chem. Technol. Biot. 89, 1419 (2009).

[12] A. A. Hassan and G. A. Sorial, Removal of benzene under acidic conditions in a controlled trickle bed air biofilter. J. Hazard. Mater. 184, 345 (2010) .

[13] L. Cabrol, L. Malhautier, F. Poly, A. S. Lepeuple and J. L. Fanlo, Assessing the bias linked to DNA recovery from biofiltration woodchips for microbial community investigation by fingerprinting. Appl. Microbiol. Biot. 85, 779 (2010). 